(c) American Dairy Science Association, 2006.

\title{
Relation Between Consumers' Perceptions of Color and Texture of Dairy Desserts and Instrumental Measurements Using a Generalized Procrustes Analysis
}

\author{
L. González-Tomás and E. Costell ${ }^{1}$ \\ Instituto de Agroquímica y Tecnología de Alimentos, Consejo Superior de Investigaciones Científicas, 46100 Burjassot (Valencia), Spain
}

\begin{abstract}
Consumers' perceptions of the color and texture of 8 commercial vanilla dairy desserts were studied and related to color and rheological measurements. First, the 8 desserts were evaluated by a group of consumers by means of the Free Choice Profile. For both color and texture, a 2-dimensional solution was chosen, with dimension 1 highly related to yellow color intensity in the case of color and to thickness in the case of texture. Second, mechanical spectra, flow behavior, and instrumental color were determined. All the samples showed a time-dependent and shear-thinning flow and a mechanical spectrum typical of a weak gel. Differences were found in the flow index, in the apparent viscosity at $10 \mathrm{~s}^{-1}$, and in the values of the storage modulus, the loss modulus, the loss angle tangent, and the complex viscosity at $1 \mathrm{~Hz}$, as well as in the color parameters. Finally, sensory and instrumental relationships were investigated by a generalized Procrustes analysis. For both color and texture, a 3-dimensional solution explained a high percentage of the total variance $(>80 \%)$. In these particular samples, the instrumental color parameters provided more accurate information on consumers' color perceptions than was provided by the rheological parameters of consumers' perceptions of texture.
\end{abstract}

Key words: dairy dessert, color, texture, generalized Procrustes analysis

\section{INTRODUCTION}

Semisolid starch-based dairy desserts are widely consumed products, generally formulated with milk, thickeners (starch and hydrocolloids), sucrose, aroma, and colorants. The characteristics of these ingredientsmilk fat content, type and concentration of starch, type and concentration of hydrocolloid, aromas, and colorants-and their interactions could produce noticeable

Received May 8, 2006.

Accepted July 20, 2006.

${ }^{1}$ Corresponding author: ecostell@iata.csic.es differences in the physical and sensory properties of these types of products, which could influence the consumer response.

In general, semisolid starch-based dairy desserts show time-dependent and shear-thinning flow behavior and viscoelastic properties typical of weak gels (Tárrega et al., 2004, 2005). Many studies have been conducted on the effect of some ingredients on the textural properties and the rheological behavior in model systems of these types of desserts (Depypere et al., 2003; Nunes et al., 2003; Verbeken et al., 2004; Vélez-Ruiz et al., 2005; Verbeken et al., 2006), but less information is available on their sensory characteristics. Using a trained panel, De Wijk et al. (2003) developed a set of sensory attributes to describe the flavor, odor, mouthfeel, and afterfeel of commercial vanilla custard desserts. Two main sensory dimensions were recognized in the resulting sensory space, both related to the texture: one running from melting to thick, and the other running from rough to creamy-soft. Weenen et al. (2005) found that some textural attributes (thick, airy, smooth, and fatty) and some taste or flavor attributes (i.e., caramel flavor) contributed positively to the creamy mouthfeel perception of these products. Interactions between sweetness and texture and between sweetness and aroma perception in model dairy desserts formulated with different sucrose levels and different textures were investigated by Lethuaut et al. (2003, 2005), who concluded that the dairy dessert containing $\lambda$-carrageenan, which had the softest texture and was perceived as being the sweetest, was also perceived as the most flavorful. Tárrega and Costell (2006) studied the effects of the interactions between $\lambda$-carrageenan, crosslinked waxy maize starch, and milk fat on the rheological and sensory properties of vanilla dairy dessert model systems and observed that concentrations of $\lambda$-carrageenan up to $0.06 \%$ increased the creaminess perceived and that, in general, samples with a higher $\lambda$-carrageenan concentration were perceived as having less flavor intensity and less sweetness. The results of these works indicated that the interactions among the ingredients significantly affected the texture and flavor of semisolid dairy desserts, as perceived by trained panels 
using descriptive techniques. However, no information has been found on the degree to which changes in these properties could influence consumers' perceptions of semisolid dairy desserts.

To assess the importance of the perceived characteristics on consumer acceptance, one possibility is to relate data obtained from a profile analysis to hedonic data. Elmore et al. (1999) studied the relationships between the intensity of 22 sensory attributes of vanilla pudding evaluated by a trained panel and the preferences of a group of consumers and concluded that the underlying sensations encompassing liking of creaminess appeared to be related to consistency, smoothness, and dairy flavor. Another approach is to obtain vocabularies directly from consumers describing their sensory perceptions and to use these vocabularies to score the samples. However, these methods suffer from problems associated with limited response options, bias attributable to the interviewer, dominant group members, difficulty in describing product characteristics, and descriptors difficult to interpret by anyone except the subject (Piggott et al., 1990; Gains, 1994). The development of Free Choice Profiling (FCP) has overcome many of these difficulties. Going one step further, the repertory grid method (RGM), coupled with the FCP, can be used as a tool to help subjects develop a more extensive vocabulary. The combination of these techniques has been applied to apples (Gomez et al., 1998), meat products (Jahan et al., 2005), and bread (Hersleth et al., 2005). The FCP assumes that consumers do not differ in the way they perceive sensory characteristics, but only in the ways they describe them (Jack and Piggott, 1992). The number of descriptors produced is limited only by the perceptual and descriptive skills of the assessor (Oreskovich et al., 1991). In this situation, consumer data cannot be averaged because each assessor could use a different number of attributes, and some of them could have different meanings. The generalized Procrustes analysis (GPA) is a statistical method that can be used to provide a perceptual map of the products. This method allows one to match the different configurations obtained from the subjects by transforming the individual spaces in 3 steps (translation, scaling, and rotation or reflection) and averaging them to produce a common or average space. The GPA can also be used effectively to evaluate the degree of the relationship between a perceptual map of products or sensory descriptive data and instrumental measurements. Some examples of this application can be found in the literature (Dijksterhuis, 1994; Faller et al., 1998; Chung et al., 2003; Le Fur et al., 2003). It is important to note that, as stated by Dijksterhuis (1995), the GPA treats both data sets (sensory and instrumental) identically and does not at- tempt to predict one set from the other; only the relationships between the 2 sets are studied.

In a previous work, González-Tomás and Costell (2006) studied how consumers perceived the sensory characteristics of commercial semisolid vanilla dairy desserts using the RGM in conjunction with the FCP. Results of the GPA showed that consumers found the largest differences among samples in color and texture.

Therefore, the purpose of this work was to obtain more specific information about the differences in color and texture among commercial semisolid vanilla dairy desserts as perceived by consumers, and to examine the relationships between these differences and the rheological and instrumental color measurements by using the GPA.

\section{MATERIALS AND METHODS}

\section{Samples}

Eight samples of vanilla dairy desserts of different brands and characteristics, covering the commercial range in the Spanish market, were purchased from local supermarkets. Five of them were formulated only with starch and hydrocolloids as thickeners, and the other 3 also contained egg to provide a more homemade flavor. The identification and composition of samples are given in Table 1. Samples were kept in the refrigerator at 4 $\pm 1^{\circ} \mathrm{C}$ prior to sensory and instrumental analyses and all tests were performed within the shelf life of each sample, which varied between 2 and 8 wk.

\section{Sensory Evaluation}

A group of 30 consumers (14 men and 16 women, ranging from 23 to $55 \mathrm{yr}$ old) was recruited from among institute administrative staff and postgraduate students. They were selected according to how frequently they consumed dairy desserts. The RGM was used to generate an individual set of terms for each consumer. Consumers used the procedure described previously (González-Tomás and Costell, 2006), which basically consisted of individual interviews (approximately 45 min each). First, the samples were grouped into 4 triads. The consumers were then asked to observe the samples and to describe, in their own terms, the similarities and differences in terms of color among the samples within each triad. Second, they were asked to describe the similarities and differences in texture. The terms generated were listed by the interviewer on individual score sheets.

In the FCP, the 8 samples were scored by each consumer in a single session in a standardized test room with separate booths using 9-point scales whose end terms were "not perceived" and "intense." Samples (30 
Table 1. Main composition ${ }^{1}$ of the commercial samples used in the study

\begin{tabular}{llll}
\hline Sample & Main ingredients & Thickeners & Colorants \\
\hline 1 & Semi-skim milk & Carrageenan, xanthan gum, modified starch & Tartrazine, cochineal red A \\
2 & Whole milk, skim milk powder, cream, jelly & Modified starch & Tartrazine, cochineal red A \\
3 & Partially skim milk, whole milk powder, cream & Carrageenan, guar gum, modified starch & Mixed carotenes \\
4 & Whole milk, dairy solids, cream & Carrageenan, modified starch & Tartrazine, cochineal red A \\
5 & Whole milk, pasteurized egg yolk, cream & Cornstarch & - \\
6 & Whole milk & Carrageenan, xanthan gum, modified starch & Annatto, curcumin \\
7 & Whole milk, skim milk, fresh egg & Carrageenan, locust bean gum, guar gum, & Tartrazine, orange yellow S \\
& Whole milk, skim milk, fresh egg & amidated pectin, modified starch, starch & Tartrazine, orange yellow S \\
& & Carrageenan, locust bean gum, guar gum, & amidated pectin, modified starch, starch \\
\hline
\end{tabular}

\footnotetext{
${ }^{1}$ As stated on the label.
}

$\mathrm{mL}$ ) were served directly from the refrigerator at $5 \pm$ $1^{\circ} \mathrm{C}$ in white plastic vessels coded with 3 -digit random numbers, and the presentation order was balanced. Samples were evaluated monadically and a rest period of $30 \mathrm{~s}$ was imposed between consecutive samples. For each sample, color attributes were evaluated first. Assessors were then asked to evaluate the texture of a sample by testing a teaspoon of it. Mineral water was provided for the assessors to rinse their mouths between samples.

\section{Color Measurements}

Color was measured in a Hunter colorimeter, Labscan II model (Hunter Associates Laboratory, Inc., Reston, VA). Samples were contained in optical glass cells $3.8 \mathrm{~cm}$ high and $6 \mathrm{~cm}$ in diameter. A 3.5- $\mathrm{cm}$ thick layer was covered with the white standard plate $(X=78.50$; $Y=83.32 ; Z=87.94$ ) for measurement of diffused reflected light from the cell bottom using a $30-\mathrm{mm}$ diaphragm aperture. Results were given in the CIELAB (Commission Internationale de l'Eclairage) system for illuminant D 65 and a $10^{\circ}$ angle of vision. Registered parameters were: $\mathrm{L}^{*}$ (brightness), $\mathrm{a}^{*}$ (red component), $\mathrm{b}^{*}$ (yellow component), $\mathrm{C}^{*}$ (chroma), and $\mathrm{h}$ (hue angle). Two measurements were performed on each sample.

\section{Rheological Measurements}

Rheological measurements were carried out in an RS1 controlled-stress rheometer (Thermo Haake, Karlsruhe, Germany), using a parallel-plate geometry of $6 \mathrm{~cm}$ in diameter and a 1-mm gap, and monitored with the RheoWin Job software package (version 2.93; Haake). Flow curves were obtained by recording shear stress values when shearing the samples at increasing shear rates from 1 to $200 \mathrm{~s}^{-1}$ in $60 \mathrm{~s}$ and down in reverse sequence in the same time. Data from the upward curve were fitted to the Ostwald-de Waele model (Equation [1]) using Rheowin Pro Data software (v. 2.93; Haake):

$$
\sigma=\mathrm{K} \dot{\gamma}^{\mathrm{n}}
$$

Rather than calculating the magnitude of the thixotropic area, defined as the area enclosed between the upward curve and the downward curve $\left(A_{u p}-A_{\text {down }}\right)$, we calculated the relative thixotropic area $\left(A_{R}\right.$; Equation [2]) because it allows a better comparison of the thixotropic behavior of different samples (Dolz et al., 2000):

$$
A_{R}=\frac{A_{u p}-A_{\text {down }}}{A_{u p}} \times 100
$$

First, the linear viscoelastic region was determined by stress sweeps run at $1 \mathrm{~Hz}$. Frequency sweeps were then performed over the range $f=0.01-10 \mathrm{~Hz}$ and the values of the storage modulus $\left(G^{\prime}\right)$, loss modulus $\left(G^{\prime \prime}\right)$, loss angle tangent $(\tan \delta)$ and complex viscosity $\left(\eta^{*}\right)$, as a function of frequency, were obtained using the Rheowin Pro Data software.

All measurements were run at $5 \pm 1^{\circ} \mathrm{C}$. After loading each sample, a waiting period of 15 min was used to allow the sample to recover and to reach the desired temperature. The measurements were then performed. Two replicates were run and a fresh sample was loaded for each run.

\section{Statistical Analysis}

A 2-way ANOVA (samples and replicates) was applied to the instrumental data. The Fisher test $(P<$ 0.05) was used to calculate the minimum significant difference. All calculations were carried out with StatGraphics Plus v. 4.1 software (StatPoint Inc., Herndon, VA).

The GPA was applied on sensory data by using Senstools v. 3.1 software (OP\&P \& Talcott, Utrecht, The Netherlands). It was performed separately for each group of descriptors, with the first analysis containing color descriptors and the second one texture descriptors. 
A simple assessment of samples provided individual matrices of 8 rows and a variable number of columns according to the descriptors generated by each consumer. To investigate the differences between subjects, the Procrustes ANOVA was used, and the differences between individual and consensus configurations as well as between samples were determined. Results of the ANOVA were expressed as a proportion of the total amount of variance previously rescaled to 100 .

The GPA was also used to investigate possible relationships between consumers' perceptions and the instrumental parameters. The analysis was performed separately for color and for texture and consisted of using as data sets 1) the average of the instrumental data across replications and 2) the perceptual multidimensional configuration obtained from the GPA of sensory data. A prescaling step was applied to the sensory and instrumental data sets prior to performing the analysis (Dijksterhuis, 1994).

\section{RESULTS AND DISCUSSION}

\section{FCP}

Color. Consumers generated and used 142 descriptors regarding the perception of color, with most of them commonly used by more than one subject (e.g., "pale yellow" or "lemon color" were cited by 9 of the 30 consumers). Individual sets ranged from 2 to 8 attributes, with an average of 5 attributes per consumer. A 7dimensional solution accounted for $64.67 \%$ : Dimension 1 comprised slightly more than half of the total variance (52.13\%) and dimension 2 accounted for only 5.57\%. The rest of the dimensions explained less than $10 \%$ of the variance and were difficult to interpret, so a 2dimensional solution was finally chosen. The scaling factors showed different ranges for the scale used by consumers, and these varied between 0.76 for the consumer who used a wider range for the scales and 2.20 for the one using a limited range.

Figure 1A shows the distribution of the residual and consensus variances over the 8 samples studied. The best level of agreement among consumers' evaluation was found in samples 5 and 8, with a large amount of the consensus variance explained, and the largest disagreement was found in sample 4, with the lower consensus variance explained and the highest residual variance. Samples 5 and 8 , which are positioned on the extremes of the first dimension (Figure 2A), have a clearly different color, and sample 4, which is located close to the center in the average space plot, represents an intermediate color. One can also observe that all the samples were mainly distributed around the first axis. To interpret the dimensions of the average space, descriptors highly correlated with each dimension were
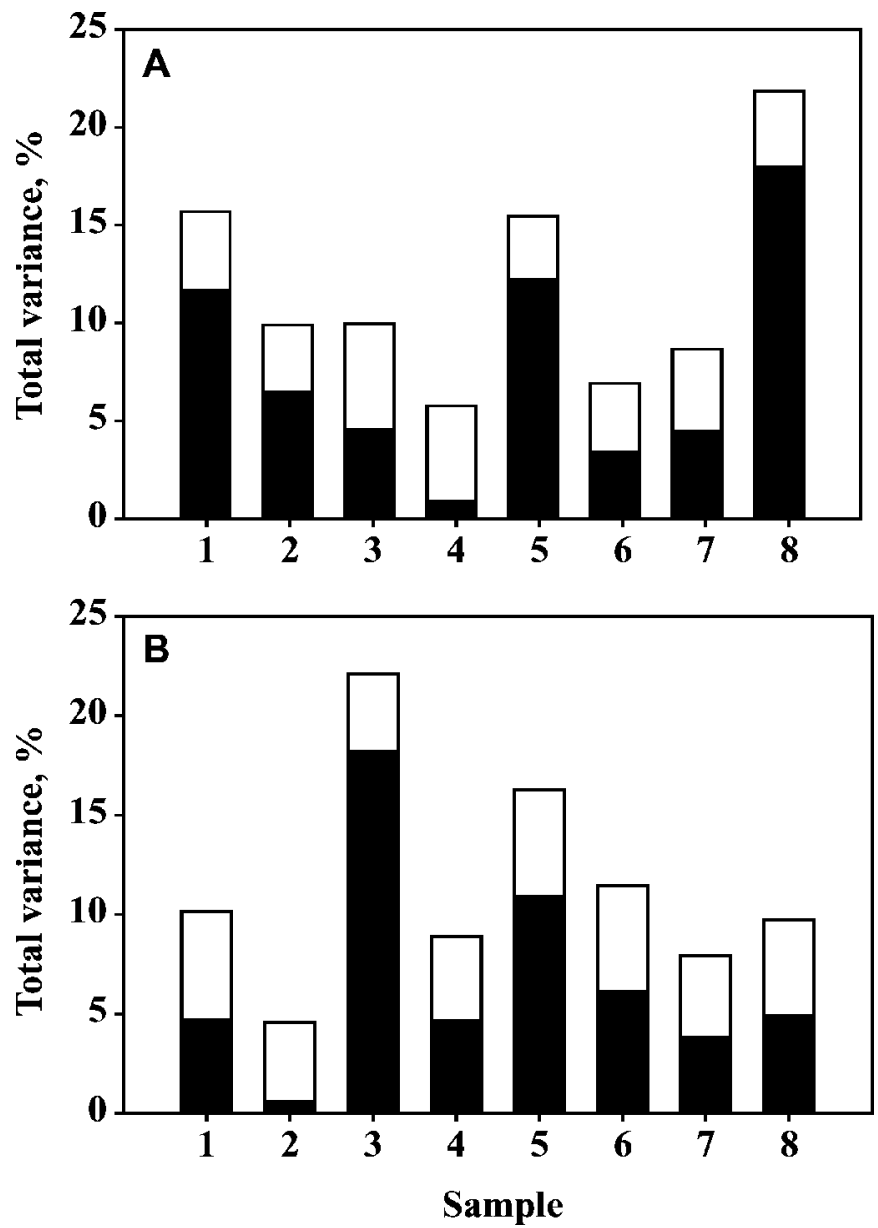

Figure 1. Consensus (black area) and residual (white area) distributed over the 8 samples. Color (A) and texture (B) evaluation. Samples identified in Table 1.

considered. Dimension 1 was correlated with yellow color intensity, with descriptors such as pale yellow $(\mathrm{r}=$ $0.94)$, soft color $(r=0.92)$, and soft yellow $(r=0.90)$ in the positive part and strong yellow $(\mathrm{r}=-0.93)$, lemon color $(r=-0.92)$, and dark color $(r=-0.91)$ in the negative part. Dimension 2, which basically separated sample 7 from the rest, explained a small amount of the variance and was strongly correlated with a yelloworange color in the negative part.

Texture. Consumers used 165 descriptors, most of which were repeated across subjects (e.g., "consistent texture" was used by $60 \%$ of the consumers), with an average of 5.5 attributes for each subject. The sum of the variances of dimension $1(33.75 \%)$ and dimension $2(11.47 \%)$ accounted for almost half of the total variance, so these 2 dimensions were selected to explain the differences among the samples. According to the scaling factor (which ranged from 0.68 to 2.28 ), isotropic transformations of individual data sets were similar to 

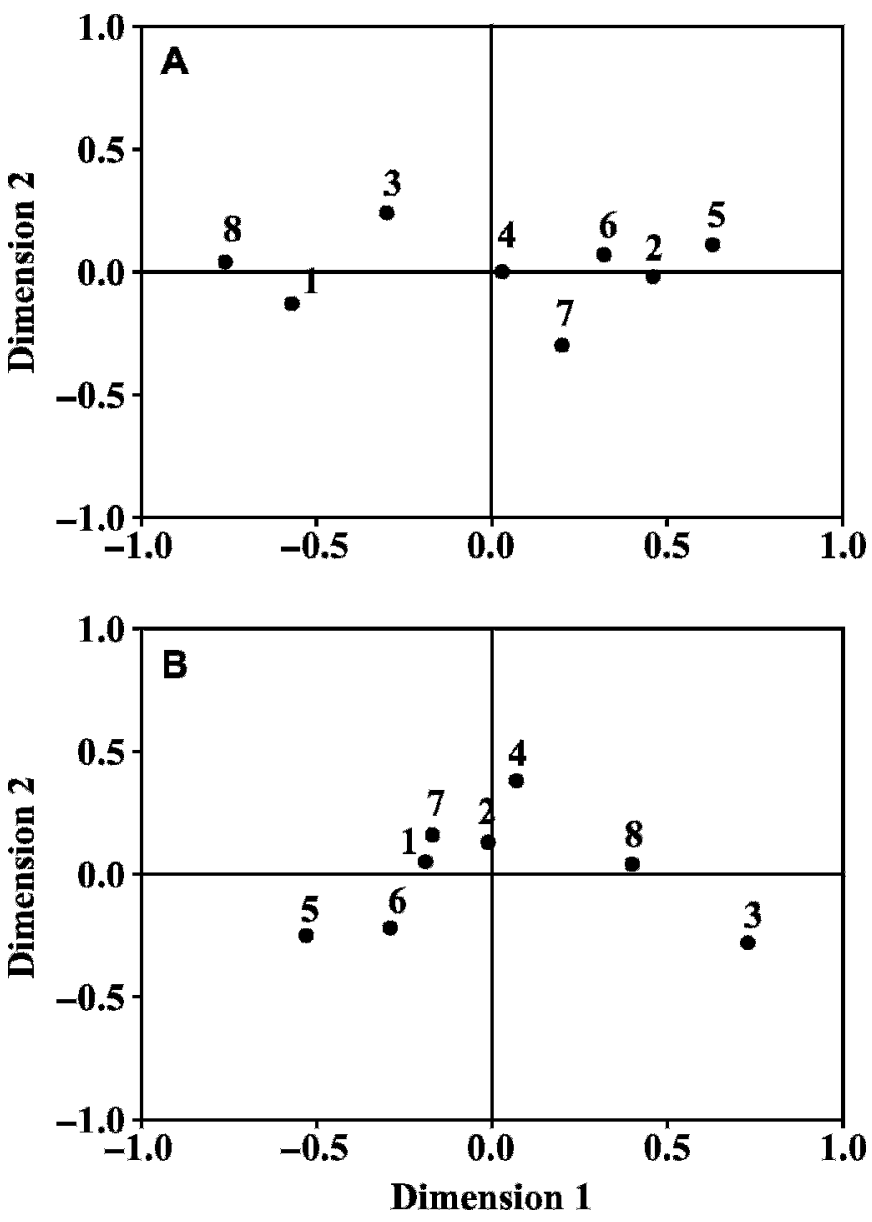

Figure 2. Average space for the evaluation of the color (A) and the texture (B) of the samples. Samples identified in Table 1.

those obtained in the color analysis; that is, consumers used the scale in a very similar way when they evaluated color and texture attributes.

The best agreement among consumers was found for samples 3 and 5, which presented consensus variances of 18.28 and 11.00, respectively, and the worst agreement was found for sample 2 , which had the greatest residual variance compared with its consensus variance (Figure 1B).

Figure 2B shows the positions of the samples in the average space. According to dimension 1, which explained most of the differences, only samples 3,5 , and 8 appeared as clearly differentiated from the others. Dimension 2 distinguished among 3 groups: one formed by sample 4 , another formed by samples $1,2,7$, and 8 , and a third group that included samples 3, 5, and 6 . Positive values on dimension 1 were highly correlated with a thick texture $(r=0.92)$, jelly texture $(r=0.92)$, or compact texture $(r=0.92)$. The negative part was correlated with descriptors such as a fluid $(\mathrm{r}=0.98)$,

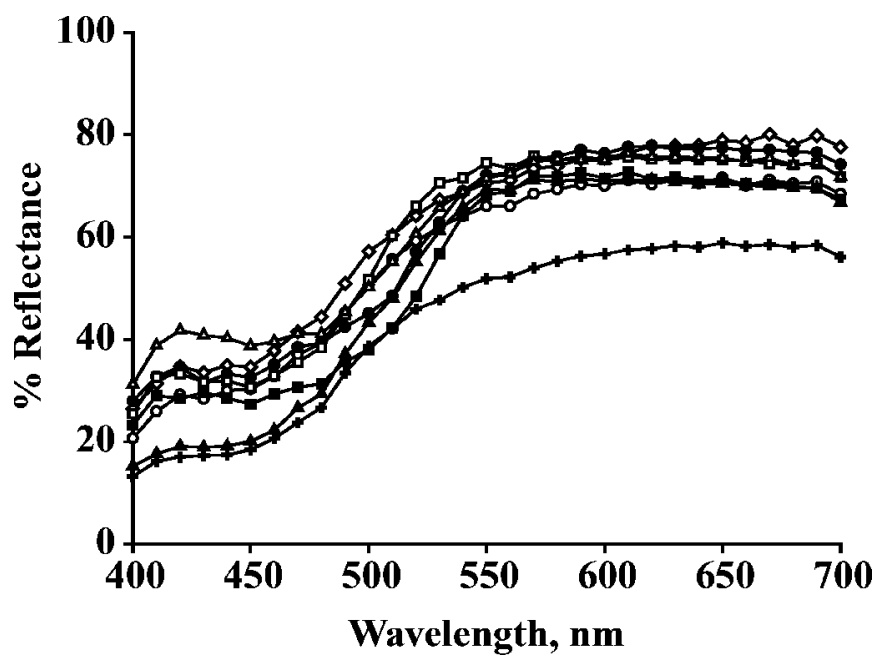

Figure 3. Spectral reflectance curves of vanilla dairy dessert sam-

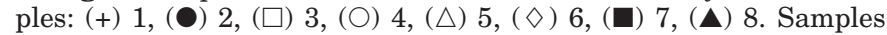
identified in Table 1.

liquid ( $\mathrm{r}=0.88)$, and soft texture $(\mathrm{r}=0.87)$. Dimension 2 was related to structural attributes such as an earthy $(\mathrm{r}=0.82)$, grainy $(\mathrm{r}=0.75)$, or rough texture $(\mathrm{r}=0.75)$ in the positive part and as a smooth $(r=0.91)$ and thin texture $(r=0.76)$ in the negative part.

\section{Instrumental Measurements}

Color. Figure 3 shows the reflectance spectra in the visible region ( 400 to $700 \mathrm{~nm}$ ) obtained for the 8 dairy dessert samples. All of them presented a plateau region, with maximum reflectance values at wavelengths over $550 \mathrm{~nm}$, the typical spectral curve for yellow-orangecolored materials. All the samples had similar curves except sample 1, which showed lower reflectance values. Differences in brightness $\left(\mathrm{L}^{*} ; F=146.2, P=0.000\right)$, redness (a*; $F=500.4, P=0.000)$, yellowness $\left(\mathrm{b}^{*} ; F=\right.$ 504.6, $P=0.000)$, chroma $\left(\mathrm{C}^{*} ; F=511.4, P=0.000\right)$, and hue $\left(\mathrm{h}^{*} ; \mathrm{F}=277.1, P=0.000\right)$ values were detected among samples when a 2-way ANOVA was applied (Table 2). A wide variation in redness values was found, with samples 5,6 , and 7 showing higher values for $a^{*}$ $\left(2.34,3.55\right.$, and 4.87 , respectively). Samples $5\left(b^{*}=\right.$ $25.91)$ and $8\left(b^{*}=46.86\right)$ were the least and most yellowcolored, respectively. Sample 1 was clearly the darker sample $\left(\mathrm{L}^{*}=75.58\right)$ and sample 7 was the most orangeyellow colored. This sample presented the highest redness value $\left(\mathrm{a}^{*}=4.87\right)$ and an intermediate value of yellowness $\left(b^{*}=35.13\right)$. These results are in agreement with the positions of these samples in the color sensory space.

Rheology. The 8 samples showed a time-dependent flow with observable hysteresis loops when sheared 
Table 2. Average values of instrumental color parameters for the commercial samples ${ }^{1}$

\begin{tabular}{llllll}
\hline Sample & $\mathrm{L}^{*}$ & \multicolumn{1}{l}{$\mathrm{a}^{*}$} & $\mathrm{~b}^{*}$ & $\mathrm{C}^{*}$ & $\mathrm{~h}^{*}$ \\
\hline 1 & $75.58^{\mathrm{d}}$ & $-0.53^{\mathrm{d}}$ & $38.37^{\mathrm{b}}$ & $38.38^{\mathrm{b}}$ & $88.13^{\mathrm{b}}$ \\
2 & $85.51^{\mathrm{a}}$ & $-0.47^{\mathrm{d}}$ & $30.23^{\mathrm{e}}$ & $30.24^{\mathrm{e}}$ & $84.85^{\mathrm{d}}$ \\
3 & $85.93^{\mathrm{a}}$ & $-2.46^{\mathrm{f}}$ & $35.62^{\mathrm{c}}$ & $35.71^{\mathrm{c}}$ & $82.44^{\mathrm{f}}$ \\
4 & $82.65^{\mathrm{c}}$ & $-1.07^{\mathrm{e}}$ & $32.78^{\mathrm{d}}$ & $32.79^{\mathrm{d}}$ & $88.47^{\mathrm{b}}$ \\
5 & $85.38^{\mathrm{a}}$ & $2.34^{\mathrm{c}}$ & $25.91^{\mathrm{f}}$ & $26.02^{\mathrm{f}}$ & $89.13^{\mathrm{a}}$ \\
6 & $84.37^{\mathrm{b}}$ & $3.55^{\mathrm{b}}$ & $32.66^{\mathrm{d}}$ & $32.85^{\mathrm{d}}$ & $83.80^{\mathrm{e}}$ \\
7 & $82.18^{\mathrm{c}}$ & $4.87^{\mathrm{a}}$ & $35.13^{\mathrm{c}}$ & $35.46^{\mathrm{c}}$ & $86.06^{\mathrm{c}}$ \\
8 & $82.61^{\mathrm{c}}$ & $-1.26^{\mathrm{e}}$ & $46.86^{\mathrm{a}}$ & $46.87^{\mathrm{a}}$ & $89.22^{\mathrm{a}}$ \\
\hline
\end{tabular}

${ }^{\mathrm{a}-\mathrm{f} V a l u e s}$ within a column with different superscript letters are significantly different at $P<0.05$.

${ }^{1}$ Samples identified in Table 1.

during an up-and-down cycle. As an example, in Figure 4 one can observe the hysteresis loops of samples 3,5 , and 2 , which presented high, average, and low levels of thixotropy. Assuming that the hysteresis loop area is an index of the energy needed to destroy the structure responsible for flow time dependence and according to the relative areas of thixotropy obtained (Table 3), samples 1,3 , and 4 presented the larger values for this area, needing the highest energy to break such a structure.

The 8 experimental upward curves revealed a nonNewtonian and shear-thinning flow and fit well to the Ostwald model $\left(0.938 \geq \mathrm{R}^{2} \geq 0.999\right)$. The flow index values (n) were in a narrow range from 0.10 to 0.32 and indicated that the sample flow was highly pseudoplastic. The consistency index values ranged from $20.33 \mathrm{~Pa} \cdot \mathrm{s}^{\mathrm{n}}$ for sample 5 to $67.92 \mathrm{~Pa} \cdot \mathrm{s}^{\mathrm{n}}$ for sample 8 . Because $K$ values depend on $\mathrm{n}$ values, the apparent viscosity values at $10 \mathrm{~s}^{-1}$ were used in the ANOVA

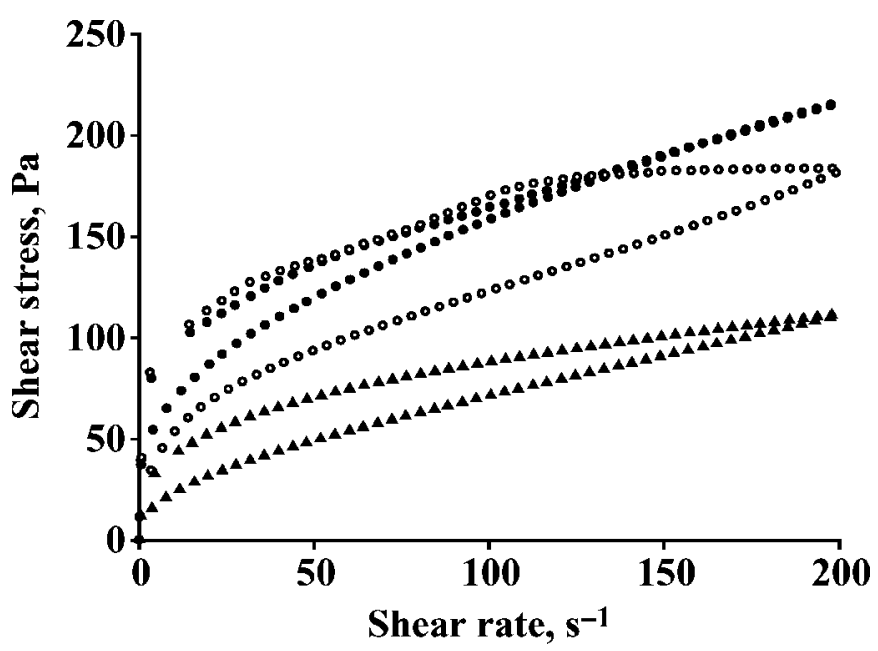

Figure 4. Flow curves of the samples with the greatest thixotropic relative area (sample $3: \bigcirc$ ), with an average thixotropic area (sample 5: $\mathbf{\Delta}$ ), and with the smallest thixotropic area (sample 2: $\bullet$ ). Samples identified in Table 1.
Table 3. Average values of relative thixotropic area $\left(A_{R}\right)$, apparent viscosity at $10 \mathrm{~s}^{-1}\left(\eta_{10}\right)$ and flow index $(\mathrm{n})$ obtained for the commercial samples ${ }^{1}$

\begin{tabular}{lccl}
\hline Sample & $A_{R}, \%$ & $\eta_{10}, \mathrm{~Pa} \cdot \mathrm{s}$ & $\mathrm{n}$ \\
\hline 1 & $20.30^{\mathrm{a}}$ & $7.51^{\mathrm{b}}$ & $0.24^{\mathrm{bc}}$ \\
2 & $3.60^{\mathrm{c}}$ & $7.52^{\mathrm{b}}$ & $0.32^{\mathrm{a}}$ \\
3 & $22.45^{\mathrm{a}}$ & $9.44^{\mathrm{a}}$ & $0.24^{\mathrm{bc}}$ \\
4 & $21.20^{\mathrm{a}}$ & $7.86^{\mathrm{b}}$ & $0.29^{\mathrm{ab}}$ \\
5 & $17.10^{\mathrm{ab}}$ & $4.14^{\mathrm{d}}$ & $0.31^{\mathrm{a}}$ \\
6 & $21.30^{\mathrm{a}}$ & $5.60^{\mathrm{c}}$ & $0.10^{\mathrm{d}}$ \\
7 & $9.35^{\mathrm{bc}}$ & $7.79^{\mathrm{b}}$ & $0.25^{\mathrm{bc}}$ \\
8 & $17.90^{\mathrm{a}}$ & $10.50^{\mathrm{a}}$ & $0.20^{\mathrm{c}}$ \\
\hline
\end{tabular}

${ }^{\mathrm{a}-\mathrm{f}}$ Values within a column with different superscript letters are significantly different at $P<0.05$.

${ }^{1}$ Samples identified in Table 1.

performed to study the differences in flow properties among the samples. This value of the apparent viscosity was selected as a possible practical index of sensory viscosity, according to the proposal of Shama and Sherman (1973). These authors suggested that the physical stimulus of sensory viscosity varies with flow characteristics, and for more viscous foods, it seems to be related to the shear stress developed at an approximately constant shear rate $\left(\dot{\gamma}=10 \mathrm{~s}^{-1}\right)$. Differences in the flow index values $(F=13.88, P=0.001)$, and in the apparent viscosity values at $10 \mathrm{~s}^{-1}(F=24.12, P=0.000)$ were detected among samples (Table 3).

Viscoelastic measurements showed a mechanical spectra typical of a weak gel, with $G^{\prime}$ values higher than $G^{\prime \prime}$ in all the cases (Figure 5). Sample 1 behaved more as a viscoelastic liquid, with $G^{\prime \prime}$ values very dependent on the frequency and with few differences between the loss and the storage modulus at high frequency rates, indicating a much weaker gel structure. In contrast, sample 2 presented the largest elastic response (Figure 5). For comparison purposes, values of $G^{\prime}, G^{\prime \prime}$, $\tan \delta$, and $\eta^{*}$ at a frequency of $1 \mathrm{~Hz}$ are shown (Table 4). The 2-way ANOVA showed differences among samples in $G^{\prime}(F=11.33, P=0.002), G^{\prime \prime}(F=17.73, P=$ $0.001), \tan \delta(F=78.94, P=0.000)$, and $\eta^{*}(F=10.49$, $P=0.003$ ). Sample 1 presented the lowest value for the complex viscosity and the highest for $\tan \delta$, which is defined as the quotient between the storage and the loss modulus, indicating that in this sample the viscous component was relatively more important than in the rest.

\section{Relationship Between Instrumental and Sensory Data}

The GPA average spaces obtained showed an explicit association between consumers' perceptions and instrumental measurements for both color (Figure 6) and texture (Figure 7). In each case, a 3-dimensional solution 


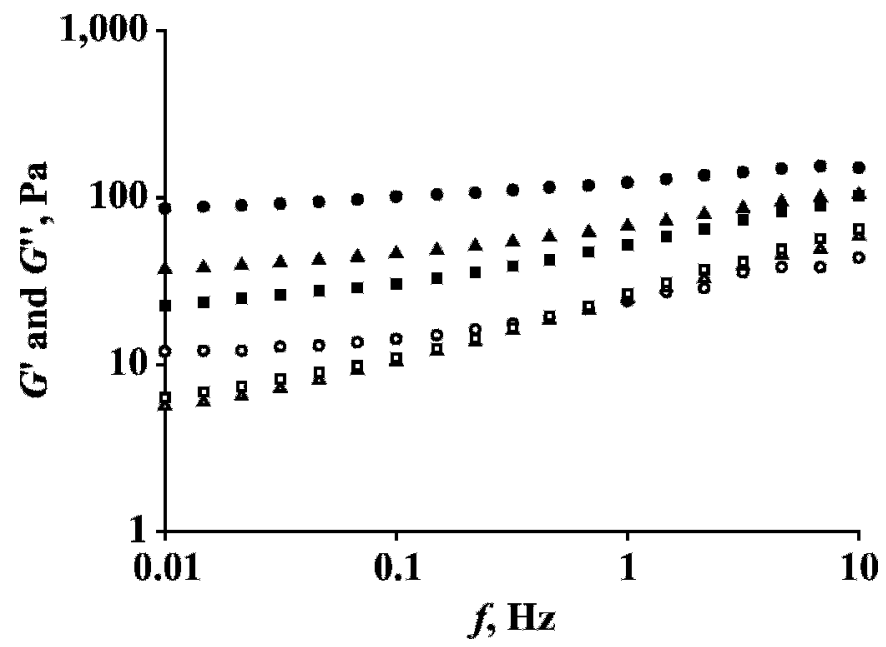

Figure 5. Mechanical spectra of the samples with the highest elastic response (sample 2: $)$ ), with an average elastic response (sample 4: $\mathbf{\Delta}$ ), and with the lowest elastic response (sample 1: $\mathbf{\square}) . G^{\prime}$ (solid symbols) and $G^{\prime \prime}$ (open symbols) experimental values. Samples identified in Table 1.

explained a high percentage of the total variance (93.26 and $83.25 \%$, respectively). According to the scaling factor $(\mathbf{S F})$ values, the sensory configurations were fairly stretched $(\mathrm{SF}>1)$ and the instrumental configurations were slightly shrunk $(\mathrm{SF}<1)$ in both attributes.

The color average spaces obtained from the first 3 dimensions (Figure 6A and $\mathrm{B}$ ) showed the position of the samples and their relationships with the sensory and instrumental configurations. The low percentage of residual variance for the 3-dimensional solution (4.01\%) indicated a good agreement between the 2 configurations. In Figure 6A, one can see that the structure of the sample configuration is very similar to the structure revealed by the average space obtained when GPA was applied to the sensory set separately (Figure 1A). With regard to the CIELAB parameters, yellowness

Table 4. Average values of $G^{\prime}, G^{\prime \prime}, \tan \delta$, and $\eta^{*}$ obtained for the commercial samples ${ }^{1}$

\begin{tabular}{lrllr}
\hline Sample & $G^{\prime}, \mathrm{Pa}$ & $G^{\prime \prime}, \mathrm{Pa}$ & $\tan \delta$ & $\eta^{*}, \mathrm{~Pa} \cdot \mathrm{s}$ \\
\hline 1 & $52.90^{\mathrm{b}}$ & $26.55^{\mathrm{bcd}}$ & $0.50^{\mathrm{a}}$ & $9.42^{\mathrm{b}}$ \\
2 & $114.50^{\mathrm{a}}$ & $23.05^{\mathrm{cde}}$ & $0.20^{\mathrm{d}}$ & $18.60^{\mathrm{a}}$ \\
3 & $107.10^{\mathrm{a}}$ & $21.90^{\mathrm{de}}$ & $0.21^{\mathrm{d}}$ & $17.40^{\mathrm{a}}$ \\
4 & $117.00^{\mathrm{a}}$ & $34.80^{\mathrm{a}}$ & $0.30^{\mathrm{b}}$ & $19.40^{\mathrm{a}}$ \\
5 & $72.35^{\mathrm{b}}$ & $20.35^{\mathrm{e}}$ & $0.28^{\mathrm{bc}}$ & $11.95^{\mathrm{b}}$ \\
6 & $74.40^{\mathrm{b}}$ & $14.50^{\mathrm{f}}$ & $0.20^{\mathrm{d}}$ & $12.05^{\mathrm{b}}$ \\
7 & $100.20^{\mathrm{a}}$ & $27.80^{\mathrm{bc}}$ & $0.28^{\mathrm{bc}}$ & $16.55^{\mathrm{a}}$ \\
8 & $113.50^{\mathrm{a}}$ & $28.70^{\mathrm{b}}$ & $0.25^{\mathrm{c}}$ & $18.65^{\mathrm{a}}$ \\
\hline
\end{tabular}

${ }^{\mathrm{a}-\mathrm{f}}$ Values within a column with different superscript letters are significantly different at $P<0.05$.

${ }^{1}$ Samples identified in Table 1 . Values determined at a frequency of $1 \mathrm{~Hz}$.
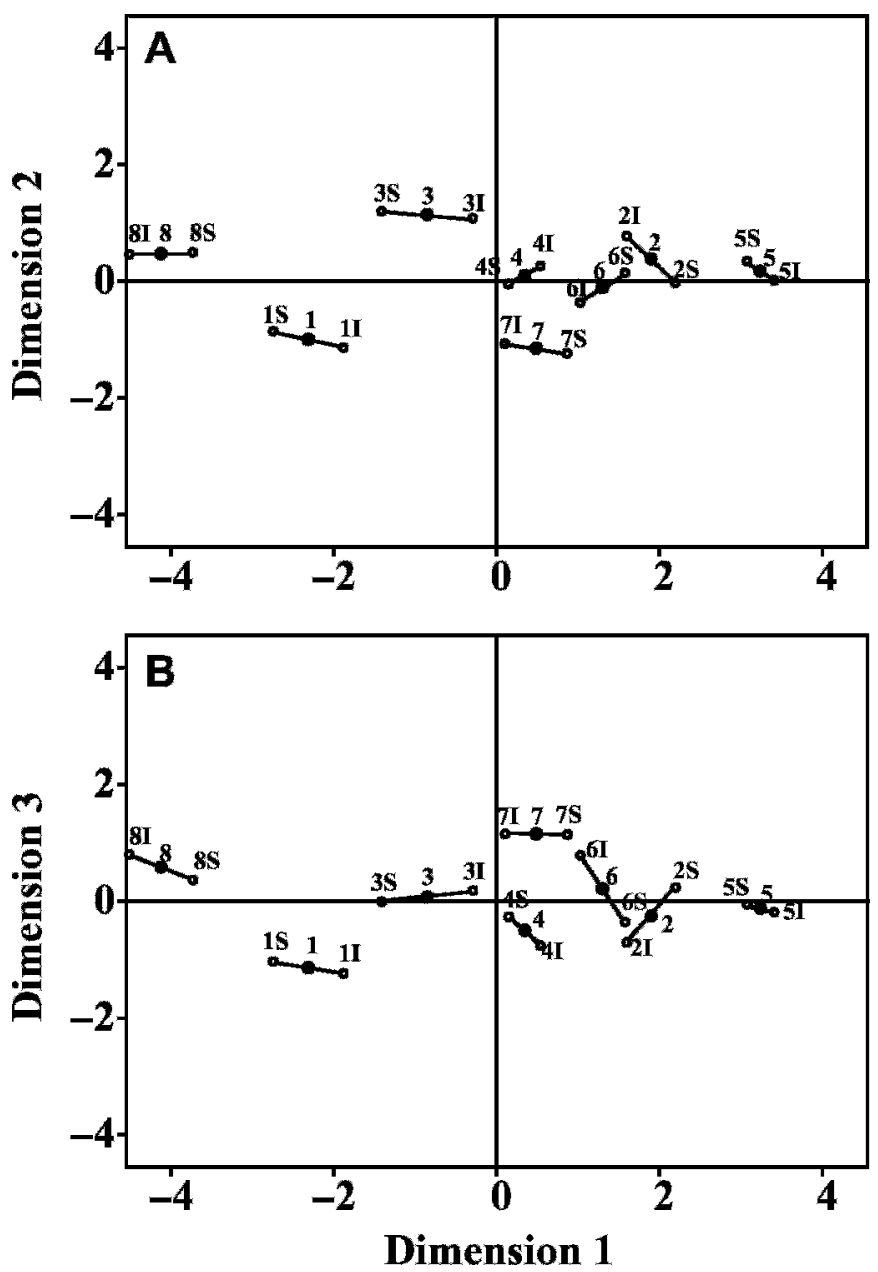

Figure 6. Position of the 8 commercial samples in the first and second dimension (A) and in the first and third dimension (B) of the color average space obtained from the generalized Procrustes analyses of instrumental and sensory data. The letters I and S indicate the position of these samples in the instrumental and sensory individual spaces, respectively.

$\left(b^{*}\right)$ and chroma $\left(C^{*}\right)$ were highly correlated $(r=-0.97$ for both parameters), with the negative part of dimension 1 and brightness $\left(\mathrm{L}^{*}\right)$ presenting a good correlation $(\mathrm{r}=0.71)$ with the positive part of dimension 2 . The instrumental variables redness $\left(a^{*}\right)$ and hue $\left(h^{*}\right)$ had a less clear relationship with the 3 dimensions of the average space and did not show much relationship with consumers' perceptions of the color of these types of dairy desserts.

The GPA texture average space (Figure 7A and B) also showed the position of the samples and their relationships with the sensory and instrumental configurations. In this case, the percentage residual variance was higher $(10.02 \%)$, as compared with the color space. A comparison between Figures 7A and $1 \mathrm{~B}$ shows that, apart from the different orientations, the structures of 

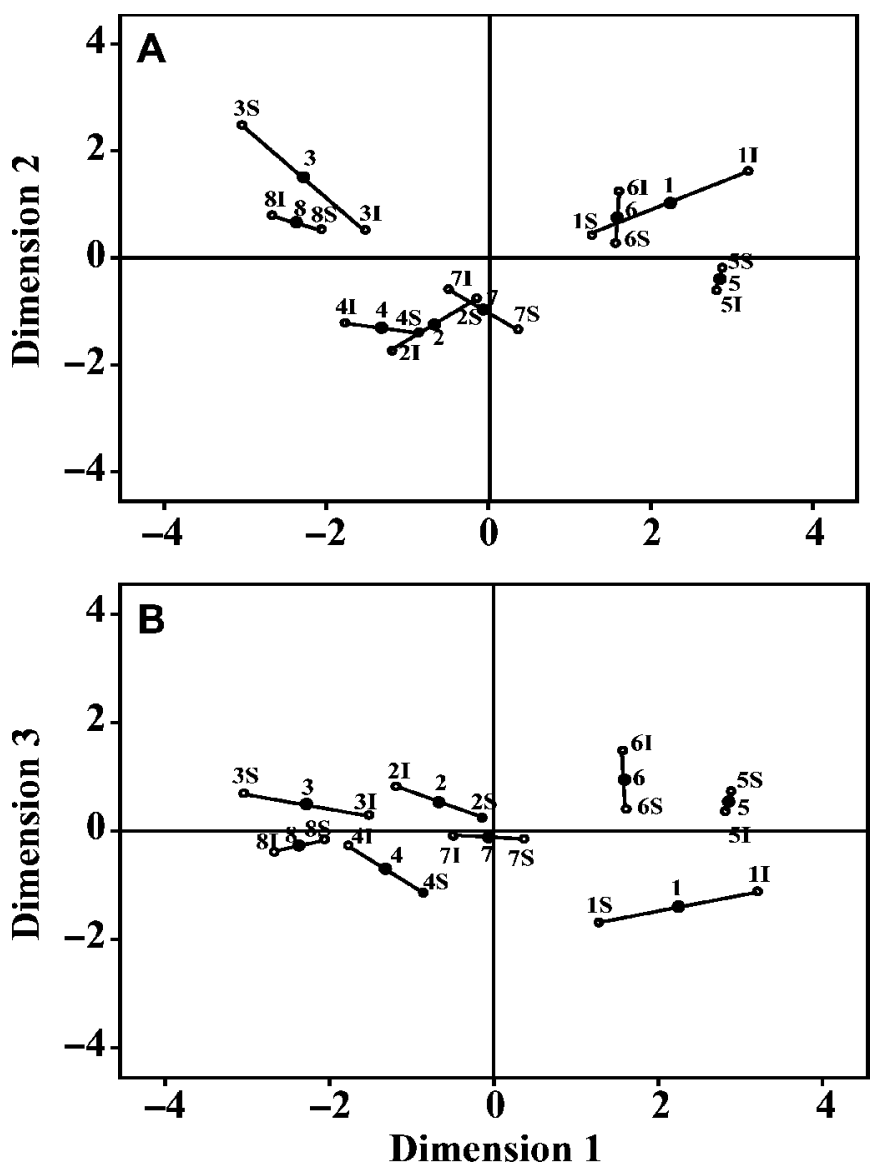

Figure 7. Position of the 8 commercial samples in the first and second dimension (A) and in the first and third dimension (B) of the texture average space obtained from the generalized Procrustes analysis of instrumental and sensory data. The letters I and S indicate the position of these samples in the instrumental and sensory individual spaces, respectively.

the sample configurations are not very different. However, one can observe that the agreement between the sensory and the instrumental measurements was clearly lower for samples 1 and 3 , which had the highest residual variances (2.73 and $3.55 \%$, respectively) and that a better agreement was obtained in sample 5 with the lowest residual variance $(0.16 \%)$. This sample was described as fluid with a soft texture by consumers and showed the lowest value for apparent viscosity, at 10 $\mathrm{s}^{-1}$ (Table 3). Values for the complex viscosity $\left(\eta^{*}\right)$, storage modulus $\left(G^{\prime}\right)$, and apparent viscosity at $10 \mathrm{~s}^{-1}$ had good correlations $(\mathrm{r}>0.85)$ with the negative part of the first dimension. Furthermore, the loss modulus $\left(G^{\prime \prime}\right)$ and loss angle tangent $(\tan \delta)$ presented the best correlations ( 0.76 and 0.87 , respectively) with the negative part of dimension 3 .

\section{CONCLUSIONS}

The combined use of the RGM and FCP allowed us to obtain valuable information about consumers' perceptions of semisolid vanilla dairy desserts. Consumers were able to detect differences in their color and texture and to describe these differences by using both methodologies. This paper supports the application of GPA in studying the relationships between sensory and instrumental data sets. For these particular samples, the instrumental color parameters provided more accurate information on consumers' color perceptions than those provided by the rheological parameters for consumers' perceptions of texture.

\section{ACKNOWLEDGMENTS}

To the Ministerio de Educación y Ciencia (formerly Ministerio de Ciencia y Tecnología) of Spain for financial support (Project AGL 2003-0052) and to the Instituto Danone for the fellowship awarded to L. González-Tomás.

\section{REFERENCES}

Chung, S. J., H. Heymann, and I. U. Grün. 2003. Application of GPA and PLSR in correlating sensory and chemical data sets. Food Qual. Pref. 14:485-495.

Depypere, F., D. Verbeken, O. Thas, and K. Dewettinck. 2003. Mixture design approach on the dynamic rheological and uniaxial compression behaviour of milk desserts. Food Hydrocoll. 17:311-320

De Wijk, R. A., L. J. Van Gemert, M. E. J. Terpstra, and C. L. Wilkinson. 2003. Texture of semi-solids: Sensory and instrumental measurements on vanilla custard desserts. Food Qual. Pref. 14:305-307.

Dijksterhuis, G. 1995. Multivariate data analysis in sensory and consumer science: An overview of developments. Trends Food Sci. Technol. 6:206-211.

Dijksterhuis, G. 1994. Procrustes analysis in studying sensoryinstrumental relations. Food Qual. Pref. 5:115-120.

Dolz, M., F. González, J. Delegido, M. J. Hernández, and J. Pellicer. 2000. A time-dependent expression for thixotropic areas. Application to aerosil 100 hydrogels. J. Pharm. Sci. 89:790-797.

Elmore, J. R., H. Heymann, J. Johnson, and J. E. Hewett. 1999 Preference mapping: Relating acceptance of "creaminess" to a descriptive sensory map of a semi-solid. Food Qual. Pref. 10:465-475

Faller, J. Y., B. P. Klein, and J. F. Faller. 1998. Characterisation of corn-soy breakfast cereals by generalized Procrustes analyses. Cereal Chem. 75:904-908.

Gains, N. 1994. The repertory grid approach. Pages 51-76 in Measurement of Food Preferences. H. J. H. Macfie and D. M. H. Thomson, ed. Blackie Academic \& Professional, Glasgow, UK.

Gomez, C., F. Fiorenza, L. Izquierdo, and E. Costell. 1998. Perception of mealiness in apples: A comparison of consumers and trained assessors. Z. Lebensm. Unters. Forsch. A 207:304-310.

González-Tomás, L., and E. Costell. 2006. Sensory evaluation of vanilla dairy desserts by free choice profile. J. Sens. Stud. 21:20-33.

Hersleth, M., F. Berggren, and M. Martens. 2005. Perception of bread: A comparison of consumers and trained asssessors. J. Food Sci. 70:95-101.

Jack, F. R., and J. R. Piggott. 1992. Free choice profiling in consumer research. Food Qual. Pref. 3:129-134. 
Jahan, K., A. Paterson, and J. R. Piggott. 2005. Sensory quality in retailed organic, free range and corn-fed chicken breast. Food Res. Int. 38:495-503.

Le Fur, Y., V. Mercurio, L. Moio, J. Blanquet, and J. M. Meunier. 2003. A new approach to examine the relationships between sensory and gas chromatography-olfactometry data using generalized Procrustes analysis applied to six French Chardonnay wines. J. Agric. Food Chem. 51:443-452.

Lethuaut, L., C. Brossard, A. Meynier, F. Rousseau, G. Llamas, B. Bousseau, and C. Genot. 2005. Sweetness and aroma perceptions in dairy desserts varying in sucrose and aroma levels and in textural agent. Int. Dairy J. 15:485-493.

Lethuaut, L., C. Brossard, F. Rousseau, B. Bousseau, and C. Genot. 2003. Sweetness-texture interactions in model dairy desserts: Effect of sucrose concentration and the carrageenan type. Int. Dairy J. 13:631-641.

Nunes, M. C., P. Batista, A. Raymundo, M. M. Alves, and I. Sousa. 2003. Vegetable proteins and milk puddings. Colloids Surf. B Biointerf. 31:21-29.

Oreskovich, D. C., B. P. Klein, and J. W. Sutherland. 1991. Procrustes analysis and its application to free choice and other sensory profiling. Pages 353-394 in Sensory Science Theory and Application in Foods. H. T. Lawless and B. P. Klein, ed. Marcel Dekker, New York, NY.
Piggott, J. R., M. R. Sheen, and S. G. Apostolidou. 1990. Consumers' perceptions of whiskies and other alcoholic beverages. Food Qual. Pref. 2:177-185.

Shama, F., and P. Sherman. 1973. Identification of stimuli controlling the sensory evaluation of viscosity II. Oral methods. J. Texture Stud. 4:111-118.

Tárrega, A., L. Durán, and E. Costell. 2004. Flow behaviour of semisolid dairy desserts. Effect of temperature. Int. Dairy J. 14:345-353.

Tárrega, A., L. Durán, and E. Costell. 2005. Rheological characterization of semisolid dairy desserts. Effect of temperature. Food Hydrocoll. 19:133-139.

Tárrega, A., and E. Costell. 2006. Effect of composition on the rheological behaviour and sensory properties of semisolid dairy dessert. Food Hydrocoll. 20:914-922.

Vélez-Ruiz, J. F., L. González-Tomás, and E. Costell. 2005. Rheology of dairy custard model systems: Influence of milk-fat and hydrocolloid type. Eur. Food Res. Technol. 221:342-347.

Verbeken, D., K. Bael, O. Thas, and K. Dewettinck. 2006. Interactions between $\kappa$-carrageenan, milk proteins and modified starch in sterilized dairy desserts. Int. Dairy J. 16:482-488.

Verbeken, D., O. Thas, and K. Dewettinck. 2004. Textural properties of gelled dairy desserts containing $\kappa$-carrageenan and starch. Food Hydrocoll. 18:817-823.

Weenen, H., R. H. Jellema, and R. A. De Wijk. 2005. Sensory subattributes of creamy mouthfeel in commercial mayonnaises, custard desserts and sauces. Food Qual. Pref. 16:163-170. 